\title{
Salivary Cortisol and Sustained Auditory Attention in Children with and without Cleft Lip and Palate
}

\author{
Viviane Mendes Fernandes ${ }^{10} \quad$ Maria Fernanda Capoani Garcia Mondelli2 ${ }^{20}$ Maria Renata José ${ }^{3}$ \\ Márcia Ribeiro Gomide ${ }^{1 \odot}$ José Roberto Pereira Lauris ${ }^{2 \odot}$ Mariza Ribeiro Feniman ${ }^{2 \odot}$ \\ 1 Postgraduate Program in Rehabilitation Sciences, Hospital de \\ Reabilitação de Anomalias Craniofaciais, Bauru, São Paulo, Brasil \\ 2 Departament of Speech Therapy, Faculdade de Odontologia de \\ Bauru, Universidade de São Paulo, Bauru, São Paulo, Brasil \\ 3 Programa de Pós-Graduação em Distúrbios da Comunicação, \\ Universidade de Tuiuti do Paraná, Curitiba, Paraná, Brasil \\ Address for correspondence Mariza Ribeiro Feniman, PhD, \\ Departamento de Fonoaudiologia, Faculdade de Odontologia de \\ Bauru, Universidade de São Paulo, Alameda Dr. Octávio Pinheiro \\ Brisolla, 9-75-Jardim Brasil - 17012-901-Bauru, SP, Brasil \\ (e-mail: feniman@usp.br).
}

Int Arch Otorhinolaryngol 2022;26(4):e605-e614.

\begin{abstract}
Keywords

- hydrocortisone

- child

- attention

- cleft lip

- cleft palate

- cognitive hearing

Introduction Cortisol is a hormone involved in the response to stress. Attention is a function that can change due to exposure to stress.

Objectives To verify the correlation between the level of salivary cortisol and sustained auditory attention in children with cleft lip and palate, as well as to compare the results of the variables analyzed between female and male patients.

Methods In total, 103 children aged 6 to 11 years, were divided into 2 groups: those with cleft lip and palate (experimental group, EG; $n=69$ ) and the control group (CG; $n=34$ ). The Sustained Auditory Attention Ability Test (SAAAT) and salivary cortisol levels, measured by an enzyme immunoassay kit (Salimetrics, Stage College, PA, US), were calculated and compared regarding the two groups. The statistical tests used were the Mann-Whitney test and the Spearman correlation.

Results The median level of salivary cortisol was of $0.03615 \mu \mathrm{l} / \mathrm{dL}$ and $0.18000 \mu \mathrm{l} / \mathrm{dL}$ respectively for the EG and $C G$, with a significant difference between the groups $(p=0.000)$. Absence of statistical significance (total error score $=0.656$; vigilance decrement $=0.051$ ) was observed the for SAAAT among the EG (median total error score $=12.00 ; 25$ th percentile $[25 \%]=7.00 ; 75$ th percentile $[75 \%]=21.00$; and vigilance decrement $=1.00 ; 25 \%=0.00 ; 75 \%=2.50$ ) and the CG (median total error score $=12.00 ; 25 \%=6.00 ; 75 \%=24.00$; and vigilance decrement $=0.00 ; 25 \%=-$ 1.00; $75 \%=2.00)$.

Conclusion All children had median levels of salivary cortisol and scores for sustained auditory attention within normal parameters. A significant correlation between the level of salivary cortisol and the ability to sustain auditory attention was observed in children without cleft lip and palate. There were no differences regarding the SAAAT and salivary cortisol between female and male patients.
\end{abstract}

received

November 2, 2020 accepted after revision April 7, 2021 published online February 9, 2022
DOI https://doi.org/ 10.1055/s-0041-1735130. ISSN 1809-9777. (c) 2022. Fundação Otorrinolaringologia. All rights reserved. This is an open access article published by Thieme under the terms of the Creative Commons Attribution-NonDerivative-NonCommercial-License, permitting copying and reproduction so long as the original work is given appropriate credit. Contents may not be used for commercial purposes, or adapted, remixed, transformed or built upon. (https://creativecommons.org/ licenses/by-nc-nd/4.0/)

Thieme Revinter Publicações Ltda., Rua do Matoso 170, Rio de Janeiro, RJ, CEP 20270-135, Brazil 


\section{Introduction}

A highly-prevalent a craniofacial anomaly worldwide $(\sim 1 / 700$ live births), cleft lip and palate (CLP) occurs between the 4th and 12th weeks of intrauterine life, when the embryonic development of the face and palate are taking place. Its etiology is multifactorial, including genetic and environmental factors. ${ }^{1}$ In general, the treatment is initiated early, and it involves several specialties. The constant hospitalizations may cause stress, fear, anxiety, morbid fantasies, and elicit feelings of helplessness and weakness from the patients and their families. $^{2}$

Cleft lip and palate are birth defects that affect different structures and functions; they can cause difficulties regarding speech, as well as issues pertaining to esthetics, eating, nutrition etc., ${ }^{3}$ which lead to others that are also important in the lives of people with malformation,s and can have significant repercussions in the process of learning, development and understanding of language. Deficits in the sustained auditory attention have been reported by researchers ${ }^{4,5}$ in children with CLP. Studies ${ }^{6,7}$ have also shown attentional impairments below what is expected for the development stage of children with CLP.

Sustained attention is the ability to concentrate on a specific stimulus over a given period of time, ${ }^{8,9}$ while excluding distracting stimuli. ${ }^{8}$ Impairments in sustained attention, therefore, may impact the child's ability to acquire and integrate new skills and knowledge. ${ }^{10}$ A previous study ${ }^{11}$ suggests that most auditory processing disorders children are not of broader attentional problems, but instead face major deficits in auditory attention tasks (sustained and auditory).

The ability to sustain attention can also be affected by exposure to stressful situations. Researchers ${ }^{12}$ have investigated the effects related to time on sustained attention and emotional processing after exposure to a situation of acute stress, and they found a decrease in the level of attention. This was observed mainly in the experimental group (EG), when cortisol was at higher levels than those observed in the control group (CG). The effects of stress on attention skills, ${ }^{13,14}$ as well as on cortisol, have also been studied. ${ }^{15,16}$

Cortisol is a corticosteroid that is distributed to all body fluids, such as urine, sweat, blood or saliva. Saliva is a valuable medium due to its easy collection and the possibility of simultaneous evaluation of multiple salivary analytes. ${ }^{17}$ Thus, saliva collection for the analysis of the level of cortisol is simple, safe, and non-invasive, and can be performed wherever the participant is. ${ }^{18}$ However, to reduce the impact of the diurnal variation in cortisol levels, it is recommended that surveys with saliva collection be performed in the afternoon, between 12 p.m. and 18 p.m., when cortisol levels are relatively stable. ${ }^{15}$ In children, researchers have frequently used salivary cortisol because its collection is painless and it is easy to store. ${ }^{19}$ Salivary cortisol is a marker of activation of the hypothalamic-pituitary-adrenal (HPA) axis, ${ }^{17}$ a neuroendocrine system that regulates the adrenocortical secretion of glucocorticoid steroids to the brain, ${ }^{20}$ and is one of the many endogenous systems reactive to stress. 21
Knowing that patients with CLP need to be hospitalized and spend long periods away from home, that the requirements of the corrective processes can generate great stress for the patient, especially in early childhood, when the fear of the unknown is a very striking fator, that cortisol levels can be elevated by stress, and that attention can change under stress, the present research aims to verify the correlation between the level of salivary cortisol and sustained auditory attention in children with CLP, as well as to compare the results of the variables analyzed between female and male patients.

\section{Methods}

The present was an observational, analytical, cross-sectional and quantitative study conducted after approval from the Ethics in Research Committee (ERC) according to letter 1.163.126; the study was conducted prospectively, with 69 volunteer children ( 31 girls and 38 boys) with an average age of 8 years and 5 months, with corrected CLP and, with the approval of the ERC, under opinion 2.967.393, with 34 children (16 girls and 18 boys), without CLP, with an average age of 8 years and 6 months.

\section{Participants}

In total, we randomly selected 483 children with some type of CLP, ${ }^{22}$ with palate-related issues, with or without Simonart band, without related syndromes, of both genders, who were undergoing treatment at a hospital specialized in craniofacial anomalies. Appointments with all of them were scheduled individually to verify the possibility that they would participate in the study and undergo the proposed exams, as well as other examinations. A total of 414 patients were excluded, as 250 of them were unable to perform the audiological evaluation, and 164 did not attend the scheduled appointment. Thus, 69 participants with CLP (71\% with transforaminal CLP, $19 \%$ with pre- and postforaminal CLP, and $10 \%$ with postforaminal CLP) were included in the study. To select children without CLP, a partnership was made with a university, in view of the difficulty to find children without such congenital malformation in the routine care of the hospital where the study took place. In total, 41 children were randomly selected through an invitation sent to the people from the community, 7 of which were excluded, as 6 did not complete the evaluation procedures due to the need to leave before the end of the service, and 1 had a mild degree of conductive hearing loss, and was referred for evaluation with an otorhinolaryngologist. Thus, the CG was composed of 34 children.

Certain inclusion criteria were the same for the children in both the EG and CG: being between 6 and 11 years old; having hearing thresholds of up to $15 \mathrm{dBHL}$ (assessed by pure-tone audiometry) and tympanometry with normal middle ear function; no difficulty in understanding the test to be applied; no hearing complaint and/or affection of the upper airways on the day of the exam (collected from the otorhinolaryngological evaluation in the medical record); and no history of complaints of inattention (reported 
by the children's guardians). For the EG, the additional inclusion criterion was having a diagnosis of CLP, ${ }^{22}$ made by professionals from the institution in which the study was conducted (information collected from the child's medical record), and, for the CG, it was not having CLP. The exclusion criteria for both groups were the presence of other malformations, syndromes and/or related neurological impairment; the presence of preforamen fissure; ${ }^{22}$ patients who had undergone dental care up to 24 hours before performing the proposed test; patients who had eaten (main meals) up to one hour before the study procedures; and children who had used oral corticosteroids up to one month before the saliva collection.

To check if all children without hearing complaints did not present any hearing loss, after verification by visual inspection of the external auditory canal that there was no impediment to the performance of the proposed hearing tests, an auditory screening was performed, consisting of research of air thresholds at frequencies $500 \mathrm{~Hz}, 1,000 \mathrm{~Hz}, 2,000 \mathrm{~Hz}$ and $4,000 \mathrm{~Hz}$, and tympanometry. To verify the information on health and ability of auditory attention, a specific questionnaire was applied. For the EG, an analysis was made of the patient's medical record, listing the number of hospital visits performed on the day the child had undergone the procedures proposed for the study so as to verify a possible correlation between the number of visits made and the level of cortisol found.

- Table 1 shows the general distribution of both groups.

\section{Procedures}

All children who met the inclusion criteria were first submitted to saliva collection and then to the Sustained Auditory Attention Ability Test (SAAAT). ${ }^{23}$

\section{Saliva Collection}

Saliva samples were obtained by the researchers and by a dental surgeon, a collaborator in the study, using the Salivette $^{24}$ (Sarstedt, Rommelsdorf, Germany) collection device, in a leveled and standardized way, following the same protocol, and always in the afternoon (between 1:30 p.m. and 5 p.m.), when cortisol levels are relatively stable. ${ }^{15}$ The children who had had small amounts of food or liquid within 30 minutes before the collection were asked to rinse with water and wait 3 to 5 minutes. The collection protocol was established: 1) explain to the guardians and child the procedure for saliva collection; 2 ) open the lid of the Salivette and remove the cotton swab; 3 ) insert the swab in the child's mouth, more precisely in the sublingual region; 4) ask the child to wait two to three minutes with the swab in the mouth (no need of chewing simulation); 5) remove the swab from the child's mouth; 6) store the swab in the plastic device and cover it; and 7) store the samples in styrofoam with ice and take them as soon as possible for storage in the laboratory, at $20^{\circ} \mathrm{C}$. For the EG, the cortisol present in the saliva samples was measured using an enzyme immunoassay kit (Salimetrics, Stage College, PA, US), at the Pharmacology and Genetics Laboratory of the institution in which the study was performed; and, for the CG, by a Biomedical in a laboratory of the Biological Sciences Sector. Cortisol levels were determined according to the manufacturer's instructions, following the standard curve. The detection limits for the age group studied vary from a minimum of $0.1 \mu \mathrm{g} / \mathrm{dL}$ to 0.7422727 $\mu \mathrm{g} / \mathrm{dL}$. The level of salivary cortisol was measured in $\mu \mathrm{g} / \mathrm{dL}$, the unit of measurement used by the manufacturer, although there are studies that use $\mathrm{nmol} / \mathrm{L}(1 \mu \mathrm{g} / \mathrm{dL}$ is equivalent to $27.59 \mathrm{nmol} / \mathrm{L}){ }^{25}$ The enzyme immunoassay kit used had sensitivity to detect cortisol levels between 0.007 and 3,000 $\mu \mathrm{g} / \mathrm{dL}$. For the EG, the number of outpatient visits performed on the day of the proposed evaluation was computed, before saliva collection, to verify its interference in the level of salivary cortisol obtained.

\section{SAAAT}

After saliva collection, the SAAAT was performed, which is a test that assesses the ability to maintain attention and focus on a task for an extended period of time. The SAAAT consists of the presentation of a list of 100 monosyllabic words, recorded in a male voice and presented in the proportion of one word per second. This list (recorded on a CD) was presented six times without interruption. The SAAAT was performed in an acoustic booth, using headphones, with the aid of a CD player coupled to a two-channel audiometer, at an intensity of $50 \mathrm{dBNS}$, considering the average of the auditory air thresholds for each ear. The test was presented in a binaural and diotic way, and had an average duration of 11 minutes. The evaluator instructed the child orally that they would hear a list of words and should raise their hand whenever they heard the word "no." To determine the result

Table 1 Distribution of the study groups according to age and gender

\begin{tabular}{|l|l|l|l|l|l|l|}
\hline \multirow{2}{*}{ Age (years) } & \multicolumn{4}{|l|}{ Control group $(\boldsymbol{n})$} & \multicolumn{3}{l|}{ Experimental group $(\boldsymbol{n})$} \\
\cline { 2 - 7 } & Male & Female & Total & Male & Female & Total \\
\hline 6 & 3 & 2 & 5 & 7 & 6 & 13 \\
\hline 7 & 2 & 3 & 5 & 3 & 0 & 3 \\
\hline 8 & 4 & 1 & 5 & 9 & 4 & 13 \\
\hline 9 & 4 & 2 & 6 & 8 & 7 & 15 \\
\hline 10 & 2 & 7 & 9 & 10 & 12 & 22 \\
\hline 11 & 3 & 1 & 4 & 2 & 1 & 3 \\
\hline Total & 18 & 16 & 34 & 39 & 30 & 69 \\
\hline
\end{tabular}


of the SAAAT, the total error score and vigilance decrement were considered. Two types of responses from the child were considered to be errors: inattention, when the child did not raise their hand in response to the target word "no;" and impulsivity, when the child raised their hand to another word instead of the word "no." A count of the number of inattention errors plus the number of impulsivity errors resulted in the total error score on the SAAAT. The vigilance decrement was obtained from the difference between the number of correct answers given for the word "no" in the first presentation of the list and the number of correct answers obtained in the sixth presentation. ${ }^{23}$

The normality test applied was the Shapiro-Wilk test, and the groups did not present a normal distribution. Thus, we used the median, and the 25th and 75th percentiles. Descriptive statistics were performed for all variables studied in both groups. The Mann-Whitney test was used to compare the groups. The correlation of the level of salivary cortisol with the SAAAT was assessed by the Spearman correlation. A significance level of 5\% was adopted.

\section{Results}

The characteristics of the study sample are presented in -Table 1. Of the 483 children with CLP initially selected, 69 were included in the study, and in the CG, of the 41 children invited to participate, 34 were included. Details regarding the recruitment are reported in -Fig. $\mathbf{1}$.

\section{Level of Salivary Cortisol}

The cortisol levels found in the EG ranged from $0.01567634 \mu \mathrm{l} / \mathrm{dL}$ to $0.1921268 \mu \mathrm{l} / \mathrm{dL}$, with a median of $0.036 \mu \mathrm{l} / \mathrm{dL}$; in the $\mathrm{CG}$, it ranged from $0.01 \mu \mathrm{l} / \mathrm{dL}$ to $0.7422727 \mu \mathrm{l} / \mathrm{dL}$, with a median of $0.180 \mu \mathrm{l} / \mathrm{dL}$.

-Table 2 shows the median levels of salivary cortisol according to age.

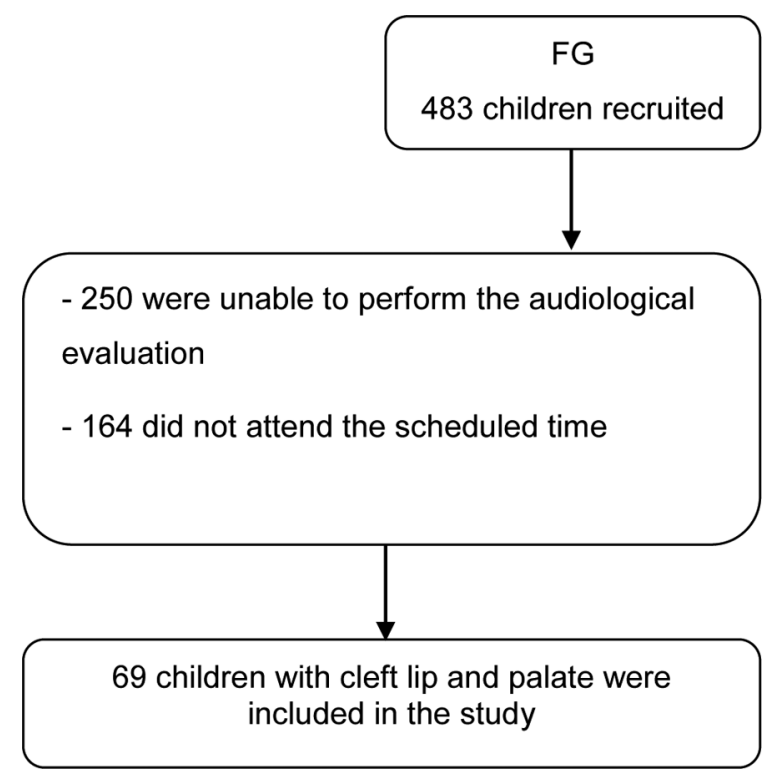

The Mann-Whitney test demonstrated a statistically significant difference when comparing the levels of cortisol ( $p=0.000$ ) between the groups, specifically at the ages of 9 $(p=0.000)$ and $10(p=0.000)$ years.

In both groups, no statistical significance was found regarding gender and levels of cortisol (EG: $p=0.412$; CG: $p=0.506$ ). One to six outpatient visits were performed by the EG, before saliva collection, on the day proposed for the evaluation. The mean daily cortisol levels ranged from $0.048 \pm 0.034 \mu \mathrm{l} / \mathrm{dL}$ to $0.055 \pm 0.039 \mu \mathrm{l} / \mathrm{dL}$. A positive correlation $(1,000 p \leq 0.05)$ between the number of visits and the levels of cortisol was found only for the 7-year-old children in this group.

\section{SAAAT}

The results of both groups on the SAAAT are shown in -Tables 3 and 4.

Only the variable impulsivity, for males, was significant $(p=0.030)$ in the comparison between genders in the EG $(n=69)$ on the SAAAT.

\section{Correlation between Salivary Cortisol and the SAAAT} Statistical significance was demonstrated by the Spearman correlation between the level of salivary cortisol and the SAAAT regarding the vigilance decrement $(p=0.010)$, but only in the CG $(n=34)$ (-Table 5).

\section{Discussion}

\section{Salivary Cortisol}

The difference between the cortisol levels obtained in this study with those of other studies ${ }^{26,27}$ may be due to differences that occurred during the analysis of saliva. The analysis kits are ultra sensitive, and aspects that might seem trivial, such as brightness and temperature, can change the final result. A study conducted ${ }^{27}$ with an enzyme immunoassay

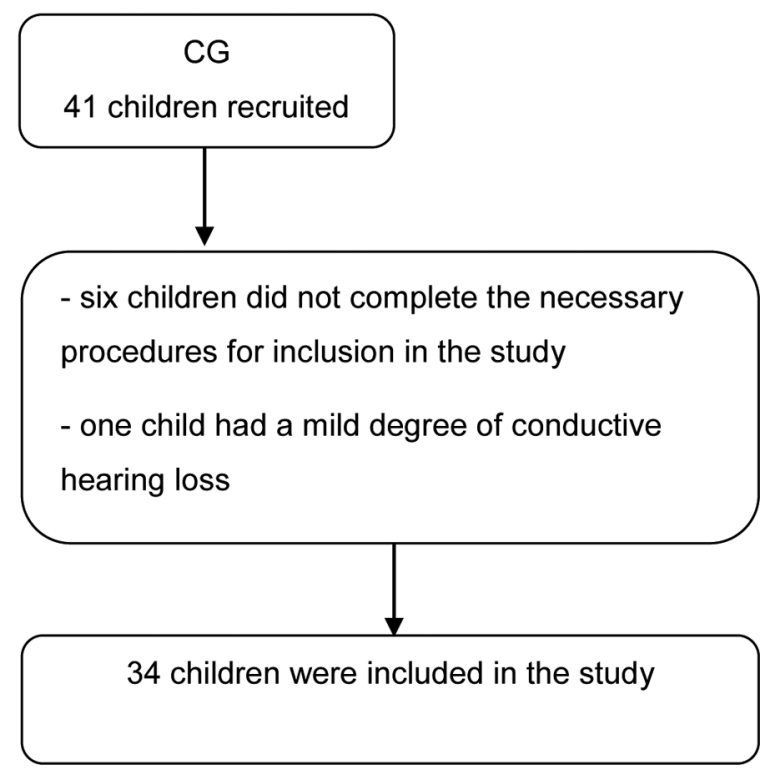

Fig. 1 Flowchart of the selection of participants for the study, and reasons for exclusions. 
Salivary Cortisol and Sustained Auditory Attention in Children with and without Cleft Lip and Palate Fernandes et al. 609

Table 2 Median, percentiles, comparison of errors (inattention, impulsivity, and total score), and vigilance decrement obtained on the SAAAT, and level of salivary cortisol $(\mu \mathrm{l} / \mathrm{dL})$, according to age

\begin{tabular}{|c|c|c|c|c|c|c|c|}
\hline \multirow[t]{2}{*}{ Age (years) } & \multicolumn{3}{|c|}{ Experimental group $(n=69)$} & \multicolumn{3}{|c|}{ Control group $(n=34)$} & \multirow[b]{2}{*}{$p$-value } \\
\hline & Median & $25 \%$ & $75 \%$ & Median & $25 \%$ & $75 \%$ & \\
\hline \multicolumn{8}{|l|}{ Inattention } \\
\hline 6 & 11.00 & 5.50 & 27.00 & 23.00 & 21.50 & 33.50 & 0.117 \\
\hline 7 & 19.00 & 9.00 & 47.00 & 8.00 & 6.50 & 22.50 & 0.250 \\
\hline 8 & 10.00 & 2.00 & 17.00 & 8.00 & 4.50 & 15.00 & 0.924 \\
\hline 9 & 9.00 & 2.00 & 13.00 & 8.50 & 4.00 & 17.75 & 0.470 \\
\hline 10 & 4.00 & 2.00 & 8.25 & 5.00 & 1.50 & 15.00 & 0.749 \\
\hline 11 & 3.00 & 2.00 & 12.00 & 5.00 & 1.25 & 8.75 & 0.629 \\
\hline Total & 8.00 & 2.50 & 14.00 & 8.00 & 4.00 & 17.50 & 0.302 \\
\hline \multicolumn{8}{|l|}{ Impulsivity } \\
\hline 6 & 6.00 & 3.00 & 8.50 & 6.00 & 3.50 & 12.00 & 0.775 \\
\hline 7 & 4.00 & 3.00 & 4.00 & 5.00 & 3.50 & 11.50 & 0.250 \\
\hline 8 & 3.00 & 2.50 & 9.50 & 2.00 & 1.50 & 6.50 & 0.208 \\
\hline 9 & 4.00 & 2.00 & 6.00 & 3.50 & 0.75 & 7.25 & 0.910 \\
\hline 10 & 2.50 & 1.00 & 5.25 & 2.00 & 0.50 & 5.50 & 0.781 \\
\hline 11 & 5.00 & 4.00 & 9.00 & 3.00 & 3.00 & 3.00 & 0.057 \\
\hline Total & 4.00 & 2.00 & 6.00 & 3.00 & 2.00 & 6.00 & 0.669 \\
\hline \multicolumn{8}{|c|}{ Total error score } \\
\hline 6 & 21.00 & 11.50 & 30.50 & 37.00 & 25.50 & 41.00 & 0.095 \\
\hline 7 & 23.00 & 13.00 & 50.00 & 12.00 & 10.50 & 34.00 & 0.393 \\
\hline 8 & 14.00 & 6.50 & 23.50 & 15.00 & 7.00 & 18.00 & 0.775 \\
\hline 9 & 11.00 & 7.00 & 19.00 & 11.50 & 6.50 & 23.50 & 0.850 \\
\hline 10 & 7.50 & 4.75 & 13.25 & 6.00 & 3.50 & 18.50 & 0.881 \\
\hline 11 & 7.00 & 7.00 & 21.00 & 8.00 & 4.25 & 11.75 & 0.629 \\
\hline Total & 12.00 & 7.00 & 21.00 & 12.00 & 6.00 & 24.00 & 0.656 \\
\hline \multicolumn{8}{|c|}{ Vigilance decrement } \\
\hline 6 & 2.00 & 0.50 & 3.00 & 0.00 & -3.00 & 6.50 & 0.633 \\
\hline 7 & 1.00 & -1.00 & 4.00 & -1.00 & -2.00 & 3.00 & 0.571 \\
\hline 8 & 0.00 & 1.00 & 4.00 & -1.00 & -1.00 & 3.50 & 0.095 \\
\hline 9 & 0.00 & 0.00 & 2.00 & 0.00 & -0.25 & 3.50 & 0.970 \\
\hline 10 & 0.00 & 0.00 & 2.00 & 0.00 & 0.00 & 2.00 & 0.915 \\
\hline 11 & 1.00 & 0.00 & 1.00 & 0.00 & -0.75 & 2.25 & 0.629 \\
\hline Total & 1.00 & 0.00 & 2.50 & 0.00 & -1.00 & 2.00 & 0.051 \\
\hline \multicolumn{8}{|c|}{ Salivary cortisol } \\
\hline 6 & 0.03 & 0.02 & 0.05 & 0.39 & 0.06 & 0.58 & 0.075 \\
\hline 7 & 0.02 & 0.02 & 0.19 & 0.14 & 0.06 & 0.27 & 0.571 \\
\hline 8 & 0.04 & 0.03 & 0.07 & 0.06 & 0.01 & 0.30 & 0.775 \\
\hline 9 & 0.03 & 0.03 & 0.08 & 0.22 & 0.17 & 0.33 & $0.000^{*}$ \\
\hline 10 & 0.03 & 0.02 & 0.05 & 0.17 & 0.14 & 0.20 & $0.000^{*}$ \\
\hline 11 & 0.02 & 0.02 & 0.03 & 0.15 & 0.03 & 0.20 & 0.400 \\
\hline Total & 0.03 & 0.02 & 0.05 & 0.18 & 0.11 & 0.24 & $0.000^{*}$ \\
\hline
\end{tabular}

Abbreviations: 25\%, 25th percentile; 75\%, 75th percentile; SAAAT, Sustained Auditory Attention Ability Test.

Notes: Statistical test: Mann-Whitney; *statistical significance. 
610 Salivary Cortisol and Sustained Auditory Attention in Children with and without Cleft Lip and Palate Fernandes et al.

Table 3 Median, percentiles, comparison of errors (inattention, impulsivity and total score), and vigilance decrement obtained on the SAAAT, and level of salivary cortisol $(\mu \mathrm{l} / \mathrm{dL})$ according to age and gender in the experimental group

\begin{tabular}{|c|c|c|c|c|c|c|c|}
\hline \multirow[t]{2}{*}{ Age (years) } & \multicolumn{3}{|c|}{ Male $(n=39)$} & \multicolumn{3}{|c|}{ Female $(n=30)$} & \multirow[b]{2}{*}{$p$-value } \\
\hline & Median & $25 \%$ & $75 \%$ & Median & $25 \%$ & $75 \%$ & \\
\hline \multicolumn{7}{|l|}{ Inattention } & \\
\hline 6 & 11.00 & 6.00 & 24.00 & 12.00 & 4.00 & 35.75 & \\
\hline 7 & 28.00 & 6.75 & 35.26 & $19.00^{*}$ & $*$ & $*$ & \\
\hline 8 & 10.00 & 4.50 & 17.50 & 6.00 & 1.25 & 16.75 & \\
\hline 9 & 3.00 & 1.25 & 15.25 & 9.00 & 6.00 & 13.00 & \\
\hline 10 & 4.00 & 2.00 & 9.25 & 4.00 & 2.25 & 8.50 & \\
\hline 11 & 2.50 & 1.50 & 2.26 & $12.00^{*}$ & $*$ & * & \\
\hline Total & 7.50 & 2.00 & 15.50 & 8.00 & 3.00 & 13.00 & 0.885 \\
\hline \multicolumn{8}{|l|}{ Impulsivity } \\
\hline 6 & 8.00 & 4.00 & 10.00 & 4.00 & 1.75 & 7.25 & \\
\hline 7 & 3.50 & 2.25 & 3.01 & 4.00 & * & * & \\
\hline 8 & 4.00 & 3.00 & 13.50 & 2.50 & 1.25 & 5.25 & \\
\hline 9 & 3.50 & 2.25 & 6.00 & 4.00 & 2.00 & 4.00 & \\
\hline 10 & 4.50 & 1.00 & 5.50 & 1.00 & 0.25 & 5.75 & \\
\hline 11 & 4.50 & 3.00 & 3.76 & 9.00 & $*$ & * & \\
\hline Total & 4.00 & 3.00 & 7.25 & 3.00 & 1.00 & 6.00 & $0.030^{* *}$ \\
\hline \multicolumn{8}{|c|}{ Total error score } \\
\hline 6 & 27.00 & 12.00 & 27.00 & 15.50 & 8.75 & 38.25 & \\
\hline 7 & 31.50 & 9.75 & 37.51 & 23.00 & $*$ & $*$ & \\
\hline 8 & 16.00 & 8.00 & 26.50 & 10.00 & 3.50 & 19.50 & \\
\hline 9 & 8.00 & 4.75 & 20.50 & 12.00 & 10.00 & 19.00 & \\
\hline 10 & 7.50 & 4.75 & 14.25 & 7.50 & 3.50 & 11.50 & \\
\hline 11 & 7.00 & 5.25 & 5.26 & 21.00 & * & * & \\
\hline Total & 13.00 & 7.00 & 25.50 & 11.00 & 7.00 & 19.00 & 0.375 \\
\hline \multicolumn{8}{|c|}{ Vigilance decrement } \\
\hline 6 & 1.00 & 0.00 & 3.00 & 3.00 & 0.75 & 5.25 & \\
\hline 7 & 0.00 & -0.75 & 0.76 & 4.00 & $*$ & $*$ & \\
\hline 8 & 1.00 & 0.50 & 3.50 & 2.00 & 0.00 & 5.50 & \\
\hline 9 & 0.00 & -0.75 & 1.75 & 0.00 & 0.00 & 3.00 & \\
\hline 10 & 0.50 & 0.00 & 2.00 & 0.00 & -0.75 & 1.00 & \\
\hline 11 & 0.50 & 0.00 & 0.76 & 1.00 & * & $*$ & \\
\hline Total & 1.00 & 0.00 & 2.00 & 1.00 & 0.00 & 3.00 & 0.743 \\
\hline \multicolumn{8}{|c|}{ Salivary cortisol } \\
\hline 6 & 0.03 & 0.02 & 0.08 & 0.03 & 0.02 & 0.04 & \\
\hline 7 & 0.02 & 0.01 & 0.02 & 0.19 & * & * & \\
\hline 8 & 0.04 & 0.03 & 0.06 & 0.05 & 0.03 & 0.12 & \\
\hline 9 & 0.05 & 0.03 & 0.09 & 0.03 & 0.02 & 0.03 & \\
\hline 10 & 0.04 & 0.03 & 0.06 & 0.03 & 0.02 & 0.05 & \\
\hline 11 & 0.02 & 0.01 & 0.03 & 0.03 & * & * & \\
\hline Total & 0.04 & 0.02 & 0.06 & 0.03 & 0.02 & 0.05 & 0.412 \\
\hline
\end{tabular}

Abbreviations: 25\%, 25th percentile; 75\%, 75th percentile; SAAAT, Sustained Auditory Attention Ability Test.

Notes: Statistical test: Mann-Whitney; ${ }^{*}$ Only one individual in this age group and of that gender; ${ }^{* *}$ statistical significance. 
Salivary Cortisol and Sustained Auditory Attention in Children with and without Cleft Lip and Palate Fernandes et al. 611

Table 4 Median, percentiles, comparison of errors (inattention, impulsivity and total score), and vigilance decrement obtained on the SAAAT, and level of salivary cortisol $(\mu \mathrm{l} / \mathrm{dL})$ according to age and gender in the control group

\begin{tabular}{|c|c|c|c|c|c|c|c|}
\hline \multirow[t]{2}{*}{ Age (years) } & \multicolumn{3}{|c|}{ Male $(n=18)$} & \multicolumn{3}{|c|}{ Female $(n=16)$} & \multirow[b]{2}{*}{$p$-value } \\
\hline & Median & $\mathrm{P} 25 \%$ & $75 \%$ & Median & $25 \%$ & $75 \%$ & \\
\hline \multicolumn{7}{|l|}{ Inattention } & \\
\hline 6 & 23.00 & 22.00 & 38.00 & 25.00 & 15.75 & 21.75 & \\
\hline 7 & 19.50 & 5.25 & 24.09 & 8.00 & 6.00 & 13.00 & \\
\hline 8 & 10.50 & 3.50 & 16.00 & $7.00^{*}$ & * & * & \\
\hline 9 & 11.00 & 5.50 & 29.25 & 5.50 & 3.00 & 5.30 & \\
\hline 10 & 8.00 & 2.25 & 9.79 & 5.00 & 0.00 & 17.00 & \\
\hline 11 & 8.00 & 2.00 & 9.00 & $1.00^{*}$ & * & * & \\
\hline Total & 11.00 & 6.25 & 22.25 & 6.50 & 4.00 & 16.00 & 0.117 \\
\hline \multicolumn{8}{|l|}{ Impulsivity } \\
\hline 6 & 6.00 & 2.00 & 15.00 & 7.00 & 3.75 & 6.75 & \\
\hline 7 & 7.50 & 2.25 & 9.09 & 5.00 & 4.00 & 11.00 & \\
\hline 8 & 2.00 & 1.25 & 2.75 & $10.00^{*}$ & * & * & \\
\hline 9 & 3.50 & 1.50 & 9.25 & 3.00 & 0.00 & 4.55 & \\
\hline 10 & 4.50 & 1.50 & 5.29 & 1.00 & 0.00 & 5.00 & \\
\hline 11 & 3.00 & 3.00 & 3.00 & $3.00^{*}$ & * & $*$ & \\
\hline Total & 3.00 & 2.00 & 6.25 & 4.50 & 1.00 & 6.00 & 0.878 \\
\hline \multicolumn{8}{|c|}{ Total error score } \\
\hline 6 & 37.00 & 25.00 & 44.00 & 32.00 & 19.50 & 28.50 & \\
\hline 7 & 27.00 & 7.50 & 33.09 & 12.00 & 11.00 & 24.00 & \\
\hline 8 & 13.00 & 5.00 & 18.00 & $17.00^{*}$ & * & * & \\
\hline 9 & 14.50 & 7.00 & 38.50 & 8.50 & 5.25 & 7.55 & \\
\hline 10 & 12.50 & 3.75 & 15.04 & 6.00 & 2.00 & 17.00 & \\
\hline 11 & 11.00 & 5.00 & 12.00 & $4.00^{*}$ & * & * & \\
\hline Total & 14.00 & 8.75 & 28.00 & 10.50 & 6.00 & 22.25 & 0.281 \\
\hline \multicolumn{8}{|c|}{ Vigilance decrement } \\
\hline 6 & 6.00 & -3.00 & 7.00 & -1.50 & -2.25 & 0.00 & \\
\hline 7 & -2.00 & -2.25 & -0.66 & 2.00 & -1.00 & 4.00 & \\
\hline 8 & -0.50 & -1.00 & 5.25 & $-1.00^{*}$ & $*$ & $*$ & \\
\hline 9 & 1.00 & -0.75 & 6.50 & 0.00 & 0.00 & 0.05 & \\
\hline 10 & 0.00 & 1.00 & 1.54 & 0.00 & 0.00 & 2.00 & \\
\hline 11 & 0.00 & -1.00 & 3.00 & $0.00^{*}$ & * & $*$ & \\
\hline Total & 0.00 & -1.00 & 3.75 & 0.00 & -0.75 & 1.50 & 0.798 \\
\hline \multicolumn{8}{|c|}{ Salivary cortisol } \\
\hline 6 & 0.42 & 0.11 & 0.74 & 0.20 & 0.00 & 0.29 & \\
\hline 7 & 0.06 & 0.00 & 0.17 & 0.20 & 0.14 & 0.34 & \\
\hline 8 & 0.13 & 0.02 & 0.35 & 0.01 & * & * & \\
\hline 9 & 0.28 & 0.20 & 0.40 & 0.17 & 0.12 & 0.18 & \\
\hline 10 & 0.14 & 0.09 & 0.15 & 0.20 & 0.15 & 0.21 & \\
\hline 11 & 0.18 & 0.12 & 0.21 & 0.01 & $*$ & * & \\
\hline Total & 0.18 & 0.11 & 0.32 & 0.17 & 0.04 & 0.20 & 0.506 \\
\hline
\end{tabular}

Abbreviations: 25\%, 25th percentile; 75\%, 75th percentile; SAAAT, Sustained Auditory Attention Ability Test.

Notes: Statistical test: Mann-Whitney; ${ }^{*}$ Only one individual in this age group and of that gender. 
Table 5 Correlation coefficient between the performance on the SAAAT and the level of cortisol

\begin{tabular}{|l|l|l|l|l|}
\hline Cortisol & Total error score & Vigilance decrement & Inattention & Impulsivity \\
\hline Experimental group & & & & \\
\hline$r$ & 0.09 & 0.02 & 0.07 & 0.07 \\
\hline$p$-value & 0.444 & 0.840 & 0.537 & 0.566 \\
\hline$N$ & 69 & 69 & 69 & 69 \\
\hline Control group & & & & \\
\hline r & 0.17 & 0.43 & 0.21 & 0.02 \\
\hline$p$-value & 0.320 & $0.010^{*}$ & 0.214 & 0.874 \\
\hline$N$ & 34 & 34 & 34 & 34 \\
\hline
\end{tabular}

Abbreviation: SAAAT, Sustained Auditory Attention Ability Test.

Notes: Statistical test: Spearman correlation; ${ }^{*}$ statistical significance.

kit (identical to the one used in the present study) in children aged 2 to 5 years showed a mean salivary cortisol ranging from $0.12 \mu \mathrm{g} / \mathrm{dL}$ to $0.24 \mu \mathrm{g} / \mathrm{dL}$. And the cortisol averages observed in another study, ${ }^{17}$ in addition to being higher compared with the parameters defined for age according to the manufacturer, were well above the results obtained in the present research (-Table 2 ). The results of the present study were within the parameters established by the manufacturer (up to $0.21 \mu \mathrm{g} / \mathrm{dL}$ ) for the age range studied. Differences in cortisol metabolism between male and female participants are already present in childhood, with a higher level of salivary cortisol in boys older than 8 years of age compared with girls. ${ }^{28}$ However, in the present study, although the salivary cortisol was slightly higher among boys, the absence of statistical significance $(p=0.41$ and $p=0.50$ respectively, for the EG and $C G$ ) regarding cortisol levels between boys and girls corroborate the findings of other studies, ${ }^{29,30}$ which also showed no significant differences in cortisol levels in the results obtained with children of different genders.

The place where the study tests were performed, a room within the hospital, could justify the statistically significant difference in the increase in the level of cortisol in the CG in relation to the EG. Thus, the place and event, strange to the child, can trigger reactions of insecurity, fear of the unknown, and cause anxiety and stress. Abnormal activity in the HPA axis has been observed in patients with anxiety. ${ }^{31} \mathrm{~A}$ study $^{32}$ showed that the levels of salivary cortisol just before the performance of the medical procedure were positively correlated with the anxiety of the partients, and the levels of salivary cortisol and anxiety were associated with increased stress. However, the testing site was not an unknown environment for children with CLP, in view of their constant and contact with the health professionals - who provide different and humanized care in the hospital, which would explain the absence of high levels of salivary cortisol in most of the EG. Taking into account the number of outpatient visits before the saliva collection for the EG, the same thing can be considered. It is noteworthy, however, that the significant correlation found only for the 7-year-old EG children may be explained by the fact that this group, at this age, was formed by only 3 individuals. In addition, one of the children had the highest level of salivary cortisol $(0.199 \mu \mathrm{g} / \mathrm{dL})$, which may have interfered with the median cortisol in this group as a whole. In a study ${ }^{33}$ that associated the stress response through cortisol and a health-related quality of life questionnaire (KIDSCREEN-52), performed with the participation children with CLP aged 5 to 10 years and a control group paired by age, the authors found that there was no difference in cortisol concentrations between children with different types of cleft. The study concluded that children with CLP did not show a higher level of stress compared with the control group.

\section{SAAAT}

In the present study, the ability to sustain auditory attention was verified by the total score of errors (inattention + impulsivity) and the vigilance decrement, obtained with the application of the SAAAT in both groups, without hearing or attention complaints, and without hearing impairment at the time of the assessment.

The results of the present study (-Tables 3 and $\mathbf{4}$ ) are in agreement with those of other studies ${ }^{34,35}$ that showed that, in continuous-performance tests, such as the SAAAT, age has a greater influence than gender. In the EG ( - Table $\mathbf{3}$ ), when comparing the age groups of 6,7 and 8 years, with 9, 10 and 11 years, this finding can be verified. However, the 7-year-old children in the EG showed worse results than the 6-year-old children, as well as the 11-year-olds in relation to the 10year-olds. It is noteworthy that, in the present study, the 7year-old children with CLP, when presenting a large number of inattention errors, contributed to the increase in the total error score, determining the age that had the worst performance. Once again, attention is drawn to the fact that a small number of children, only three, were of this age, an aspect that may contribute to this finding. For the CG, younger children scored higher (worse) regardingthe total error score, ${ }^{36}$ except for the 9-year -olds (-Table 4), who had a higher score than the 8-year-olds. This result is due to the greater number of inattention and impulsivity errors, when compared with those of the 8-year-olds. However, a study ${ }^{37}$ that used the same instrument to assess sustained auditory 
attention in 50 children aged 7 years without CLP concluded that the children evaluated in the afternoon and those studying in public schools had a worse performance in the ability to sustain auditory attention, showing that the period of the day and the type of school can be a possible source of variation in the child's ability to sustain auditory attention. Following the methodology applied in a previous study, ${ }^{36}$ this study was applied in the afternoon, but the type of school (public or private) was not investigated in children with or without CLP. In this study, ${ }^{36}$ regarding the value obtained for the vigilance decrement, the other parameter considered in the performance on the SAAAT, the older children in both groups showed scores within normal values for all ages evaluated. Other researchers ${ }^{4}$ have reported that, for the vigilance decrement, 7-year-olds with CLP had a worse performance on the SAAAT than those without CLP. In this study, although the boys in most of the age groups tested showed a more inattentive and impulsive behavior (verified in the values of the errors made on the test), and the girls in most age groups tested had a better performance (verified in the total error score), the differences found between genders in both groups were not significant. This was also reported in other studies ${ }^{4,23,37}$ that used the SAAAT. Some studies ${ }^{38,39}$ reported significantly higher scores on inattention in boys with CLP compared with the controls. In the present study, the impulsivity error was significant $(p=0.030)$ among the male children in the EG. Difficulties related to inhibitory control are generally associated with impulsivity, found in tasks of continuous performance, and are called commission errors, that is, when the subject responds to a stimulus that was not the specified target. ${ }^{40}$ In continuous-performance tasks, when the impulsive action is measured as an absolute number of inhibitory failures, males show greater impulsivity, according to a study. ${ }^{41}$ Another study ${ }^{38}$ reports that boys with isolated CLP have higher levels of hyperactivity, impulsivity and inattention compared with controls, and this is directly related to a significant increased volume of the right ventromedial prefrontal cortex, the region of the brain involved in impulse control behaviors.

A significant difference was expected in the SAAAT results of both groups, considering that, in the population with craniofacial anomalies, especially in those with CLP, the high occurrence of middle-ear alterations is well known, with consequent conductive hearing loss. ${ }^{42}$ Authors suggest in their study that the main aspects of auditory and cognitive skills are impaired by the minimal and mild, symmetrical and asymmetrical hearing loss. Also, long periods of sensory deprivation, in addition to conductive hearing loss, can lead to perceptual hearing deficits ${ }^{44}$ and interfere in the development of the structures and functions of the central nervous system. ${ }^{45}$ It is noteworthy that, in the questionnaire applied to the parents or guardians of the children with and without CLP, in this study, almost $41 \%$ reported the presence of otitis media during early childhood. Moreover, a study ${ }^{4}$ demonstrated that the SAAAT performance of 7-year-old children with a type of CLP similar to the one herein analyzed was inferior to that of children without CLP.
Correlation between Salivary Cortisol and the SAAAT

The statistical significance obtained in the correlation between the levels of salivary cortisol and vigilance decrement in the CG ( - Table 5), showing that the higher the level of salivary cortisol, the more the attention of these children declined during the test. It is noteworthy, however, that the values of salivary cortisol and vigilance decrement were within the normal range for both groups. The absence of a correlation between the level of cortisol and the quality of life of children with CLP has also been demonstrated in a previous research. ${ }^{33}$

The present study makes some considerations that must be observed in future trials, such as the fact that obtaining a more homogeneous sample with a larger number of individuals may provide more accurate information about the correlation between the level of cortisol and sustained auditory attention. The application of questionnaires to assess anxiety and obtain data on quality of life may contribute with additional information on stress and increased levels of cortisol. It would also be interesting to conduct a study to verify the impact of the hospital environment on the child's anxiety, with double collections, using the same child as a control, and comparing the samples collected in a familiar environment with the ones obtained in the hospital environment.

A limitation of the present study is that we did not apply instruments to assess the socioeconomic characteristics and/or psychological factors that could affect the stress level of children, focusing only on the laboratory analysis of the level of cortisol and the ability to sustain auditory attention; the evaluation of these characteristics is suggested in future studies.

\section{Conclusions}

All children had median levels of salivary cortisol and scores for sustained auditory attention within normal parameters. A significant correlation between the level of salivary cortisol level and the ability to sustain auditory attention was observed in the CG. There was no difference regarding the performance on the SAAAT and the level of salivary cortisol between female and male subjects.

Conflict of Interests

The authors have no conflict of interests to declare.

\section{Acknowledgments}

Acknowledgments to Conselho Nacional de Desenvolvimento Científico e Tecnológico (CNPq) for the granted for the development of this study - Grant No. 306750/2015-5.

\section{References}

1 Freitas JA, das Neves LT, de Almeida AL, et al. Rehabilitative treatment of cleft lip and palate: experience of the Hospital for Rehabilitation of Craniofacial Anomalies/USP (HRAC/USP)-Part 1: overall aspects. J Appl Oral Sci 2012;20(01):9-15

2 Tabaquim MLM, Marquesini MAM. Study of the stress of parents of patients with cleft lip and palate in a surgical process. Estud Psicol 2013;30(04):517-524

3 Vyas T, Gupta P, Kumar S, Gupta R, Gupta T, Singh HP. Cleft of lip and palate: A review. J Family Med Prim Care 2020;9(06):2621-2625 
4 Lemos ICC, Feniman MR. Teste de Habilidade de Atenção Auditiva Sustentada (THAAS) em crianças de sete anos com fissura labiopalatina. Rev Bras Otorrinolaringol (Engl Ed) 2010;76(02):199-205

5 Moraes TFD, Maximino LP, Feniman MR. A habilidade de atenção auditiva sustentada em crianças com fissura labiopalatina e transtorno fonológico. Rev Soc Bras Fonoaudiol 2011;16(04):436-440

6 Jacob MF, Tabaquim MLM. Atenção e linguagem em crianças com fissura labiopalatina. Atenção e linguagem em crianças com fissura labiopalatina. Ver Saúde Des Hum. 2014;2(01):15-27

7 Gannam LM, Teixeira MF, Tabaquim MLM. Psic. da Ed., São Paulo, 40, $1^{\circ}$ sem. de 2015:87-101

8 Shalev L, Ben-Simon A, Mevorach C, Cohen Y, Tsal Y. Conjunctive Continuous Performance Task (CCPT)-a pure measure of sustained attention. Neuropsychologia 2011;49(09):2584-2591

9 Cohen RA. Focused and sustained attention. In: The Neuropsychology of Attention. New York, NY, USA: Springer; 2014:89-112

10 Betts J, McKay J, Maruff P, Anderson V. The development of sustained attention in children: the effect of age and task load. Child Neuropsychol 2006;12(03):205-221

11 Stavrinos G, Iliadou V-M, Edwards L, Sirimanna T, Bamiou D-E. The relationship between types of attention and auditory processing skills: reconsidering auditory processing disorder diagnosis. Front Psychol 2018;9:34

12 Alomari RA, Fernandez M, Banks JB, Acosta J, Tartar JL. Acute Stress Dysregulates the LPP ERP Response to Emotional Pictures and Impairs Sustained Attention: Time-Sensitive Effects. Brain Sci 2015;5(02):201-219

13 Ajilchi B, Nejati V. Executive functions in students with depression, anxiety, and stress symptoms. Basic Clin Neurosci 2017;8 (03):223-232

14 Rodrigues S, Paiva JS, Dias D, Pimentel G, Kaiseler M, Cunha JPS. Wearable biomonitoring platform for the assessment of stress and its impact on cognitive performance of firefighters: an experimental study. Clin Pract Epidemiol Ment Health 2018;14:250-262

15 Henckens MJAG, van Wingen GA, Joëls M, Fernández G. Timedependent effects of cortisol on selective attention and emotional interference: a functional MRI study. Front Integr Nuerosci 2012; 6:66

16 Dolcos F. The fast and the slow sides of cortisol's effects on emotional interference and sustained attention. Front Neurosci 2014;8:268

17 Strahler J, Skoluda N, Kappert MB, Nater UM. Simultaneous measurement of salivary cortisol and alpha-amylase: Application and recommendations. Neurosci Biobehav Rev 2017;83:657-677

18 Bozovic D, Racic M, Ivkovic N. Salivary cortisol levels as a biological marker of stress reaction. Med Arh 2013;67(05):374-377

19 Bates R, Salsberry P, Ford J. Measuring stress in young children using hair cortisol: the state of the science. Biol Res Nurs 2017;19 (05):499-510

20 Jacobson L. Hypothalamic-pituitary-adrenocortical axis: neuropsychiatric aspects. Compr Physiol 2014;4(02):715-738

21 Herman JP, McKlveen JM, Ghosal S, et al. Regulation of the hypothalamic-pituitary-adrenocortical stress response. Compr Physiol 2016;6(02):603-621

22 Spina V, Psillakis JM, Lapa FS, Ferreira MC. Classificação das fissuras lábio-palatinas. Sugestão de modificação. Rev Hosp Clin Fac Med Sao Paulo 1972;27(01):5-6

23 Feniman MR, Ortelan RR, Lauris JRP, Campos CF, Cruz MS. Proposta de instrumento comportamental para avaliar a atenção auditiva sustentada. Rev Bras Otorrinolaringol 2007;73(04):523-527

24 Sarsted. Salivette ${ }^{\circledR}$ - Hygienic saliva collection for diagnostics and monitoring. Nümbrecht, Germany: Sarsted; 2005

25 Salimetrics. Expanded range high sensitivity salivary cortisol enzyme immunoassay kit. (C) Salimetrics, Inc. [online]. [consultado em 12 ago. 2016]. Disponível: URL: https://www. salimetrics.com/assets/documents/1-3002n.pdf
26 Gomes HS, Corrêa-Faria P, Silva TA, et al. Oral midazolam reduces cortisol levels during local anaesthesia in children: a randomised controlled trial. Braz Oral Res 2015;29(01):S1806-8324201 5000100305

27 Gomes HS, Vieira LA, Costa PS, Batista AC, Costa LR. Professional dental prophylaxis increases salivary cortisol in children with dental behavioural management problems: a longitudinal study. BMC Oral Health 2016;16(01):74

28 van der Voorn B, Hollanders JJ, Ket JCF, Rotteveel J, Finken MJJ. Gender-specific differences in hypothalamus-pituitary-adrenal axis activity during childhood: a systematic review and metaanalysis. Biol Sex Differ 2017;8:3

29 McCarthy AM, Hanrahan K, Kleiber C, Zimmerman MB, Lutgendorf S, Tsalikian E. Normative salivary cortisol values and responsivity in children. Appl Nurs Res 2009;22(01):54-62

30 Curcio WB, Scalioni FAR, Soares MRPS, Devito KL, Chaves MGAM, Ribeiro RA. Salivary cortisol levels in children undergoing dental treatment - a pilot study. Pesq Bras Odontoped Clin Integr. 2013; 13(01):5-10

31 Juruena MF, Eror F, Cleare AJ, Young AH. The Role of Early Life Stress in HPA Axis and Anxiety. Adv Exp Med Biol 2020;1191:141-153

32 Kara D, Bayrak NA, Volkan B, Uçar C, Cevizci MN, Yildiz S. Anxiety and Salivary Cortisol Levels in Children Undergoing EsophagoGastro-Duodenoscopy Under Sedation. J Pediatr Gastroenterol Nutr 2019;68(01):3-6

33 Sundell AL, Marcusson A, Törnhage CJ. Salivary cortisol rhythms in children with cleft lip and/or palate: a case-control study. Cleft Palate Craniofac J 2018;55(08):1072-1080

34 Rueda FJM, Monteiro RMM. Bateria psicológica para avaliação da atenção (BPA): desempenho de diferentes faixas etárias. PsicoUSF 2013;18(01):99-108

35 Coelho DG, Lima RF, Ims RE, Fonseca GUS, Ciasca SM. Desempenho de estudantes em instrumentos de atenção e funções executivas: análise do efeito da idade. Rev Sul-Am Psicol 2014;2(02):214-239

36 Feniman MR, Ortelan RR, Campos CF, Cruz MS, Lauris JRP. A habilidade de atenção auditiva sustentada em crianças. ACTA ORL/Técnicas em Otorrinol 2007;25(04):280-284

37 Picolini MM, Stivanin D, Sampaio AR, et al. Auditory Attention: Time of Day and Type of School. Int Arch Otorhinolaryngol 2010; 14(02):174-179

38 Nopoulos P, Boes AD, Jabines A, et al. Hyperactivity, impulsivity, and inattention in boys with cleft lip and palate: relationship to ventromedial prefrontal cortex morphology. J Neurodev Disord 2010;2(04):235-242

39 Ha P, Zhuge X-Q, Zheng Q, Shi B, Gong C-X, Wang Y. Behavioral pattern in Chinese school-aged children with cleft lip and palate. Asian Pac J Trop Med 2013;6(02):162-166

40 Malloy-Diniz LF, de Paula JJ, Sedó M, Fuentes D, Leite WB. Neuropsicologia das funções executivas e da atenção. In: Fuentes D, Malloy-Diniz LF, Camargo CHP, Cosenza RM. organizator. Neuropsicologia - Teoria e Prátic [2ed.]. Porto Alegre: Artmed; 2014: 115-38

41 Weafer J, de Wit H. Sex differences in impulsive action and impulsive choice. Addict Behav 2014;39(11):1573-1579

42 Brown TH. Childhood hearing impairment. Paediatr Child Health 2020;30(01):6-13

43 Moore DR, Zobay O, Ferguson MA. Minimal and mild hearing loss in children: association with auditory perception, cognition, and communication problems. Ear Hear 2020;41(04):720-732

44 Popescu MV, Polley DB. Monaural deprivation disrupts development of binaural selectivity in auditory midbrain and cortex. Neuron 2010;65(05):718-731

45 Clarkson C, Antunes FM, Rubio ME. Conductive Hearing Loss Has Long-Lasting Structural and Molecular Effects on Presynaptic and Postsynaptic Structures of Auditory Nerve Synapses in the Cochlear Nucleus. J Neurosci 2016;36(39):10214-10227 